Research article

\title{
Reuse of sustainable materials for xylenol orange dye and copper (II) ion ammoniacal removal
}

\author{
M.I. Garrudo-Guirado a , A. Blanco-Flores b, c, *, H.P. Toledo-Jaldin ${ }^{\text {d }}$, \\ V. Sánchez-Mendieta ${ }^{\mathrm{e}, * *}$, A.R. Vilchis-Néstor ${ }^{\mathrm{e}}$ \\ a Facultad de Ingeniería Química, Universidad Tecnológica José Antonio Echeverría, calle 114, entre 119 y 127, C.P. 19390, Marianao, La Habana, Cuba

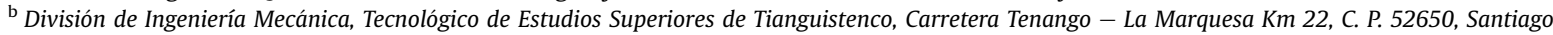 \\ Tianguistenco, Estado de México, Mexico \\ ' Instituto de Metalurgia, Universidad Autónoma de San Luis Potosí, Avenida Sierra Leona 550, C. P. 78210, Lomas 2a sección, San Luis Potosí, Mexico \\ d Facultad de Química, Universidad Autónoma del Estado de México, Paseo Colón y Tollocan s/n, C.P. 50180, Toluca, Estado de México, Mexico \\ e Centro Conjunto de Investigación en Química Sustentable UAEM-UNAM, Carretera Toluca, Atlacomulco Km 14.5, C. P. 50 000, San Cayetano, Toluca, Estado \\ de México, Mexico
}

\section{A R T I C L E I N F O}

Article history:

Received 20 June 2017

Received in revised form

18 October 2017

Accepted 26 November 2017

Keywords:

Adsorption

Vitreous tuff

Solid waste

Discontinuous systems

\begin{abstract}
A B S T R A C T
Water pollution caused by heavy metals and organic compounds is an environmental problem with negative impact, making the restoration of water quality a priority. In this paper, the adsorption of xylenol orange dye (XO) on vitreous tuff mineral (VT) was studied. It was established that the adsorption capacity of VT was $45.17 \mathrm{mg} / \mathrm{g}$. The removal was carried out by interactions between active sites on the surface of the material and the functional groups of the dye. The solid waste obtained from this process (VTXO) was reused as adsorbent material for $\mathrm{Cu}$ removal in the form of the complex $\mathrm{Cu}-\mathrm{NH}_{3}$ because this process was done in an ammoniacal medium. It was found that the adsorption capacity of this new material was $33.09 \mathrm{mg} / \mathrm{g}$. In a previous research, VT mineral was used to remove crystal violet (CV) instead of XO. The solid waste of this last process (VTCV) was also applied for $\mathrm{Cu}-\mathrm{NH}_{3}$ removal, in order to compare the adsorption capacity of VT after the adsorption of two different kinds of dyes. The adsorption capacity of VTXO was lower than that of VTCV $(71.23 \mathrm{mg} / \mathrm{g})$. In both processes, adsorption kinetic was well described by a chemical adsorption onto a heterogeneous surface. The equilibrium time for XO removal was $50 \mathrm{~min}$ and $80 \mathrm{~min}$ for $\mathrm{Cu}-\mathrm{NH}_{3}$. The experimental design stated that the maximum adsorption capacity was reached when the initial concentration was $6400 \mathrm{mg} / \mathrm{L}$ and the solid-liquid ratio was $10 \mathrm{~g} / \mathrm{L}$. The system that requires the least amount of adsorbent was the counter flow batch. Finally, it was possible to estimate the behavior of the system on a higher scale. This research provides an efficient and economical alternative to treat water contaminated with dyes and cooper in an ammoniacal medium using the same material in both processes, one after the other.
\end{abstract}

() 2017 Elsevier Ltd. All rights reserved.

\section{Introduction}

Nowadays, water consumption is growing in every economic sector worldwide. In recent years water pollution has increased with the industrial development, population growth and

\footnotetext{
* Corresponding author. División de Ingeniería Mecánica, Tecnológico de Estudios Superiores de Tianguistenco, Carretera Tenango-La Marquesa Km 22, C. P. 52650 , Santiago Tianguistenco, Estado de México, Mexico.

** Corresponding author.

E-mail addresses: blancoflores81@hotmail.com (A. Blanco-Flores),vsanchezm@ uaemex.mx (V. Sánchez-Mendieta).
}

unplanned urbanization (Ávila, 2011). Many different kinds of pollutants could be found in wastewater, like dyes and heavy metals ions, coming from textile and paper industries mainly. These pollutants have negative impact on the environment and the living beings. Therefore it is essential the development of efficient, adequate, cheap and environmental friendly new technologies ( $\mathrm{Wu}$ et al., 2014).

Dyes are discharged in textile effluents, some of them are difficult to remove from aqueous medium due to its chemical complex structure, formed by aromatic rings with heteroatoms. Dyes in aquatic ecosystems cause concern because its toxicity, carcinogenic and mutagenic effects. Furthermore, dyes reduce light 
penetration and photosynthesis processes in aquatic plants (Aguiar et al., 2017). For this reason, dyes removal is an important challenge for the environmental science and technology.

Xylenol orange is an organic reagent, most commonly used as a salt for heavy metals determination. It is applied in some processes of manufacturing and textile industries. This dye is toxic not only for aquatic life but also for human beings. It is known to exert its toxicity through complex formation with heavy metals. Inorganic toxic pollutants, like heavy metals, are generated from mining and galvanizing industries. In contrast to organic compounds, heavy metal are not biodegradable, they are very difficult to destroy and can bioaccumulate entering to the trophic chain (Ge et al., 2015). Effluents from metal plating and printed circuit contain high concentrations of cooper in aqueous and ammoniacal medium (Metwally et al., 2013). In large quantities, copper may cause gastrointestinal problems, ulcers, kidney damage, or even death. Most water treatments, for this kind of effluent, involve precipitation, but this method is usually ineffective because it brings the pollutant from the water to the solid phase named waste sludge. The final disposal of sludge becomes another environmental problem.

Organic and inorganic pollutants removal can be achieved by adsorption process. In the literature, there are only few reports of XO removal by this process (Zhang et al., 2016). However, it is the most attractive method for wastewater treatment because its simplicity, low cost of operation and ability to provide efficient processes (Feng et al., 2017). Normally, a high adsorption capacity is proportional to its surface area and superficial functional active sites. For this reason, in some cases the surface of materials need to be modified by adding functional groups. For this purpose, it is necessary the use of reactants or additional processes, these may increase costs. However, some pollutants, previously adsorbed in the surface material, have these functional groups already and the process with this reused material may be a promising option. Traditionally, the adsorption of more than one pollutant implies the application of more than one adsorbent materials. But, if the same material could be reused for another process the amount of employed material could be significantly reduced.

After an adsorption process the material became a solid waste. Usually, this is subjected to a desorption process or discarding, incinerating and also fixing. However, this solid waste can be applied as a new adsorbent material. A surface structure modification allows the adsorption of other species. In addition the affinity of some dye molecules to attract heavy metals, like xylenol orange, could be exploited.

The aim of this work is to establish the potentialities and efficiency of a recycled material, coming from a dye adsorption process with VT, for cooper removal as $\mathrm{Cu}-\mathrm{NH}_{3}$ from an ammoniacal effluent of an industrial process. It provides important information about adsorption processes of cooper in ammoniacal medium that has been reported very few times. However, this kind of medium is very common in industrial processes.

\section{Material and methods}

For $\mathrm{Cu}-\mathrm{NH}_{3}$ adsorption experiments first, we studied the effectiveness of VT to remove XO. The material named VTXO was used to decrease levels of copper ions in an ammoniacal solution.

\subsection{Vitreous tuff mineral}

VT was obtained from a deposit in Cuba. The material was milled and sieved to 60 mesh.

\subsection{Characterization of vitreous tuff mineral and modified material}

TG/DSC analyses of VT mineral were realized in Netzsch model STA 449 F3 Jupiter, at $0-600{ }^{\circ} \mathrm{C}$ temperature range. The aluminium crucible was employed in the analyses under nitrogen atmosphere.

Textural properties measurements were done by using the nitrogen physisorption technique at $77 \mathrm{~K}$ in a Quantachrome Autosorb-1. The average pore diameter of VT was determined with the method of Barrett, Joyner and Halenda $(\mathrm{BJH})$ and by the Kelvin equation. The total pore volume was obtained at 0.99 relative pressure. The sample was previously degassed out at $200{ }^{\circ} \mathrm{C}$ for $3 \mathrm{~h}$ to remove water and $\mathrm{CO}_{2}$.

Concentrations of the acid-base groups of VT were determined according to the method described in previous paper (BlancoFlores et al., 2016).

Scanning electron microscopy (SEM) images were acquired in a JEOL JSM-6510 microscope operated at $20 \mathrm{kV}$. Samples were fixed on a support with a carbon film and sputter-coated with gold to a thickness of $200 \AA$ A. Elemental microanalyses were performed at randomly selected areas on the solid surfaces, in order to elucidate the atomic distribution of both materials, with an energy X-ray dispersive spectroscopy (EDS) system attached to JSM-6510 microscope. All micrographs were collected on the same experimental conditions with the backscattered electron detector.

\subsection{Characterization of the wastewater used for the investigation}

The wastewater was collected from a printed circuit production industry which generates $\mathrm{Cu}-\mathrm{NH}_{3}$ on a large scale. For the determination of conductivity and $\mathrm{pH}$ a Conductronic $\mathrm{pH} 120$ equipment was used. Infrared spectra in the $4000-400 \mathrm{~cm}^{-1}$ range was recorded at room temperature using Bruker Tensor 27 FTIR. The sample did not require previous preparation. Chemical composition was determined by inductively coupled plasma-atomic emission spectrometry, using a Spectroflame FTMO8, Spectrophotometer.

\subsection{Kinetics adsorption of $\mathrm{XO}$ dye and $\mathrm{Cu}$ (II) ion}

The wastewater in ammoniacal medium was diluted to prepare a solution with initial concentration of $6400 \mathrm{mg} / \mathrm{L} .25 \mathrm{~mL}$ of dye and metal solution (ion initial concentrations were 700 and $6400 \mathrm{mg} / \mathrm{L}$ respectively) were added to $25 \mathrm{mg}$ of VT and VTXO separately. Then, the mixture was shaken at different times at $120 \mathrm{rpm}$ and room temperature. Later, samples were centrifuged and decanted. Experiments were performed in duplicate. Pseudo first order, pseudo second order and second models were applied for experimental kinetic data in order to study the kinetic process (Blanco-Flores et al., 2016).

\subsection{Adsorption isotherms}

$25 \mathrm{mg}$ of each material were put in contact with $25 \mathrm{~mL}$ of solutions with different initial concentrations: 700-6400 mg/L for XO and $640-6400 \mathrm{mg} / \mathrm{L}$ for cooper ion in ammoniacal solution. They were stirring during equilibrium time at room temperature. The mixture was centrifuged and decanted. The dye and metal ion concentrations in the solutions were determined using an UV/Vis Perking Elmer Lambda 10 ultraviolet-visible spectrophotometer at 500 and $622 \mathrm{~nm}$, respectively.

The amount of dye and metal ion adsorbed at time interval $\mathrm{q}_{\mathrm{t}}$ $(\mathrm{mg} / \mathrm{g})$ and equilibrium $\mathrm{q}_{\mathrm{e}}(\mathrm{mg} / \mathrm{g})$ were calculated by equation $(1)$ :

$\left(C_{o}-C\right) \cdot V / m=q$

where, $C_{0}(m g / L)$ is the initial dye or metallic ion concentration, $C$ 
$(\mathrm{mg} / \mathrm{L})$ is the concentration of the solution after the contact, $\mathrm{V}(\mathrm{L})$ is the volume of treated solution, and $\mathrm{m}(\mathrm{g})$ is the mass of adsorbent material.

The Langmuir, Freundlich, Langmuir-Freundlich, Temkin and Redlich-Peterson adsorption isotherm models (Can et al., 2016; Anirudhan and Ramachandran, 2015; Pejman et al., 2015) were used to study the adsorption experiments.

\subsection{Experimental design}

A $3^{2}$ factorial design was performed to determine the best experimental conditions for $\mathrm{Cu}-\mathrm{NH}_{3}$ adsorption with VTXO. The variables were solid-liquid ratio and metallic ion initial concentration. The proposed design was single stage batch adsorber by simple contact with fixed volume $(400 \mathrm{~mL})$. The used reactor was a stirred-like tank with standardized design to mix the wastewater with VTXO. The dimensions of reactor were $8 \mathrm{~cm}$ of diameter and $8 \mathrm{~cm}$ of liquid height. The three propeller blades stirred were selected without baffles. The diameter of stirrer was $4 \mathrm{~cm}$.

\section{Results and discussion}

\subsection{Characterization of VT, VTXO and VTXOCu materials}

The VT mineral is an aluminosilicate with narrow mesopores; it has a rough surface and is made up by aggregation of different kind of particles. Its surface area is $64.40 \mathrm{~m}^{2} / \mathrm{g}$. The material surface showed plenty of superficial silanol groups responsible for the adsorption process (Blanco-Flores et al., 2014).

The stability of VT at a temperature range was analyzed and compare with results referred in literature. In Fig. 1 curves of TGA and DSC are presented for selected sample. According to these results, the mineral VT does not show significant changes at the selected temperature range.

Fig. 1 showed a slight endothermic peak about $100{ }^{\circ} \mathrm{C}$ correlated with water evaporation. From $400{ }^{\circ} \mathrm{C}$ an increased is observed where some process may take place. Heide and Heide (2011) refered the presence of two different water species clearly distinguished by thermic analyses in volcanic rocks as perlite, pitchstone and tuff material. The water release occurs by diffusion between 80 and $800{ }^{\circ} \mathrm{C}$, in our case about $100{ }^{\circ} \mathrm{C}$. A spontaneous release is observed between $500{ }^{\circ} \mathrm{C}$ and $1450{ }^{\circ} \mathrm{C}$. It matched with the second endothermic peak observed at about $400^{\circ} \mathrm{C}$. The weight loss, in this

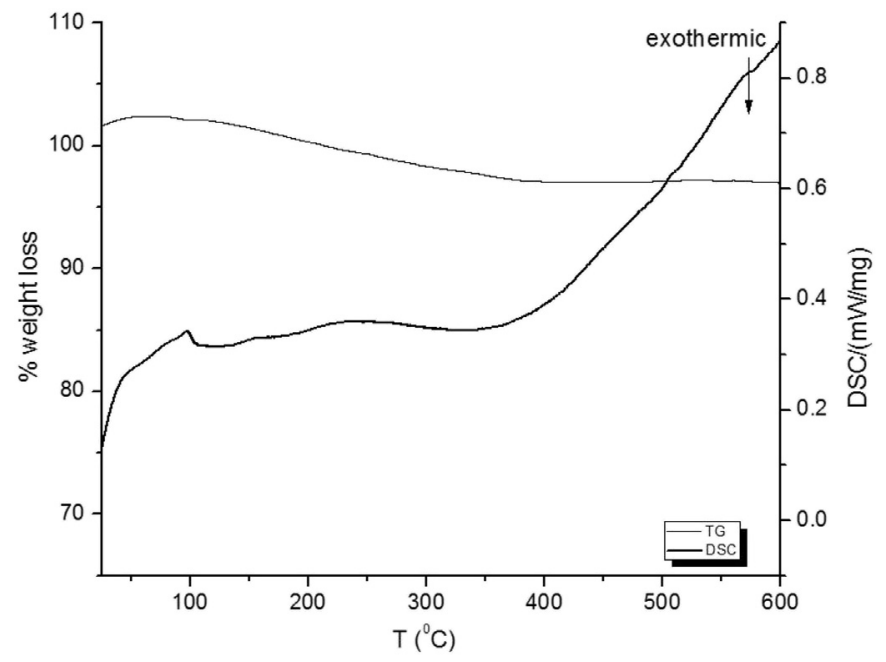

Fig. 1. TG and DSC curves of VT mineral. range of temperature, is not observed because the VT can only present a phenomenon related to activation or expansion. The process occurred above $800{ }^{\circ} \mathrm{C}$ is typical in expanded volcanic rocks like expanded perlite (Pichór and Janiec, 2009).

Pore size distribution was established (Fig. 2a). Pore size distribution was mesopores for VT. The total volume $\left(0.088 \mathrm{~cm}^{3} / \mathrm{g}\right)$ and diameter $(1.52 \mathrm{~nm})$ pore values indicated the presence of mesopores according to Tsai et al. (2003). Specifically the value of $D_{p}$ indicated the presence of narrow mesopores. According to the wide of hysteresis (Blanco-Flores et al., 2016), between branch of adsorption-desorption $\mathrm{N}_{2}$ isotherm, the sizes of pores are different (Fig. 2b). The low adsorption at low pressures and the presence of condensation zone, confirm the mesoporosity. Both aspect should contributed to the adsorption dye process.

The acidity and basicity of the VT was 164 and $140 \mathrm{meq} / \mathrm{g}$, respectively. The amphoteric behavior of surface groups should be responsible for the similar values of acidity and basicity groups. The presence of $\mathrm{H}$ and $\mathrm{O}$ elements provides the acidity surface (Tedros et al., 2017) and influences the adsorption dye process.

In all the studied samples, a rough surface was observed. They were consist of many different sizes and forms of particles aggregates. In Fig. 3a-b, neither VT nor VTXO material exhibited a visible porosity. However, after Xo adsorption, some type of spider web
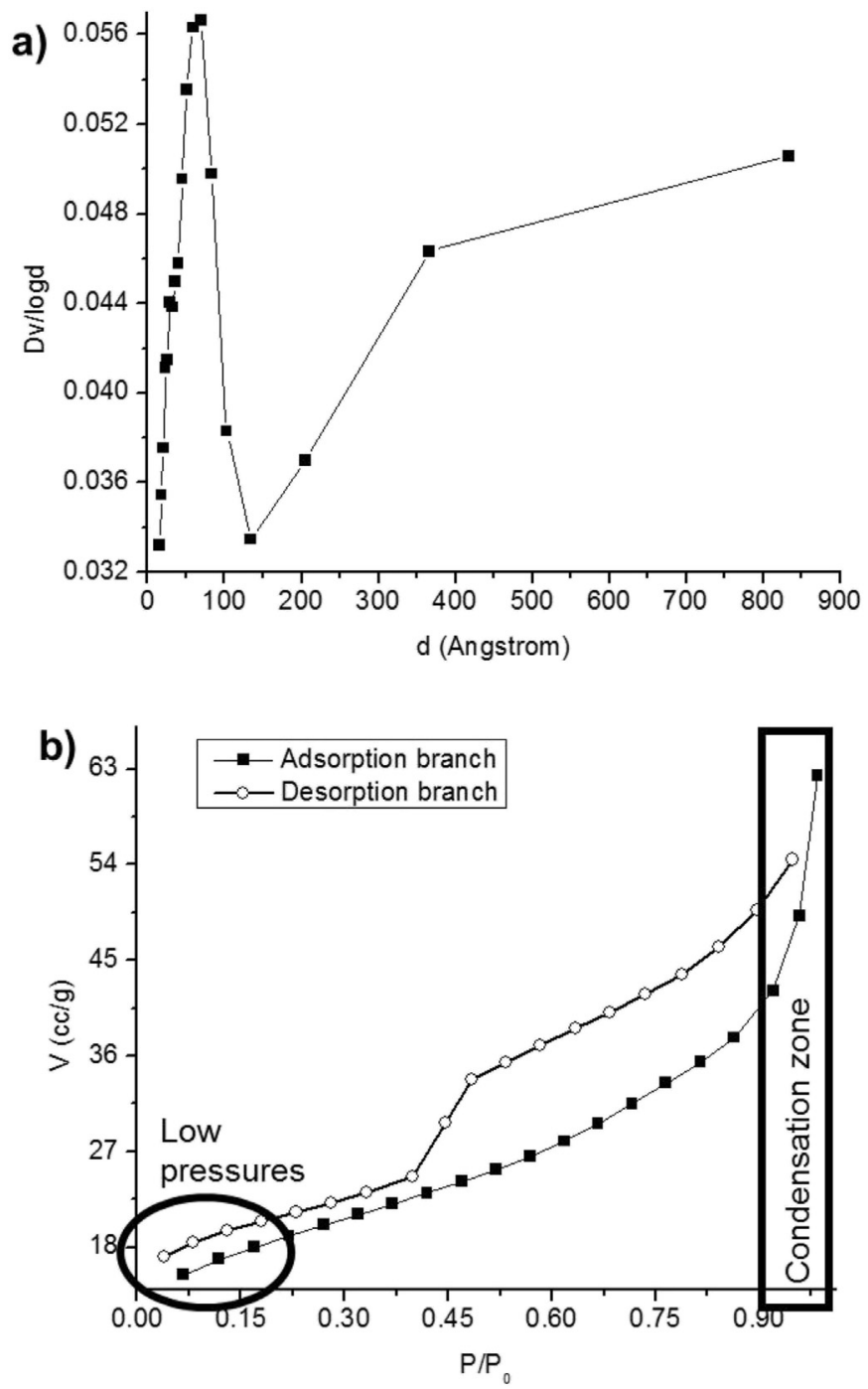

Fig. 2. Pore size distribution (a) and $\mathrm{N}_{2}$ adsorption-desorption hysteresis (b). 

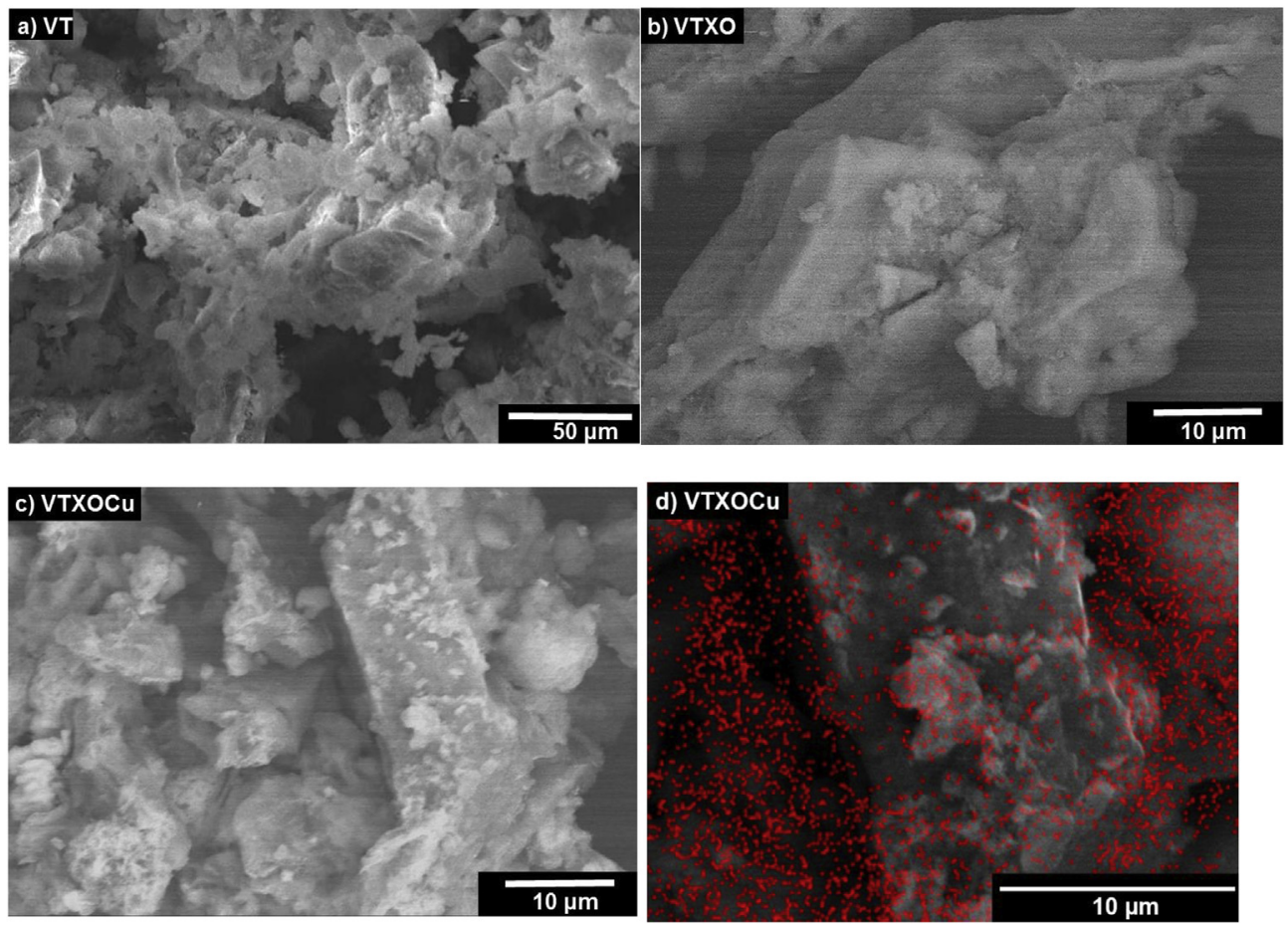

Fig. 3. SEM images of VT (a), VTXO (b), VTXOCu (c) and chemical maps of VTXOCu materials, BEC, 20 kV, x5000.

was observed on the material surface. In contrast, some differences could be noted in VTXOCu (Fig. 3c), these could be associated to $\mathrm{Cu}$ moieties on the adsorbent material. Chemical mapping of VTXOCu material confirmed the set out above (Fig. 3d). In this case the adsorbed $\mathrm{Cu}-\mathrm{NH}_{3}$ could be observed in almost all the surface material homogeneously distributed.

Moreover, chemical elemental composition of VT, VTXO and VTXOCu (Table 1) reveals the amounts of alkaline and alkalineearth elements and $\mathrm{Cu}-\mathrm{NH}_{3}$. Maybe these compounds can be related to the dye and metal ion adsorption process. The presence of copper in VTXOCu confirms its inclusion in the solid phase and therefore its removal from aqueous solution.

\subsection{Characterization of wastewater}

The concentration of $\mathrm{Cu}-\mathrm{NH}_{3}$ was $120 \mathrm{~g} / \mathrm{L}$, the $\mathrm{pH}$ value around 8.65 and the conductivity was $76.9 \mathrm{mS}$. Infrared spectrum of the wastewater showed some characteristic signals of the ion-complex tretraaminecopper (II) $\left[\left(\mathrm{Cu}\left(\mathrm{NH}_{3}\right)_{4}\right]^{2+}\right.$.

Table 1

Elemental composition by EDS analyzes for VT mineral, VTXO and VTXOCu wastes.

\begin{tabular}{llll}
\hline \multirow{2}{*}{ Elements } & \multicolumn{2}{l}{ Weight percent (\%) } \\
\cline { 2 - 4 } & VT & VTXO & VTXOCu \\
\hline $\mathrm{C}$ & 9.85 & 15.99 & 3.89 \\
$\mathrm{O}$ & 52.41 & 42.17 & 29.84 \\
$\mathrm{Na}$ & 0.17 & 0.71 & 0.16 \\
$\mathrm{Mg}$ & 0.73 & 2.01 & 0.17 \\
$\mathrm{Al}$ & 5.21 & 5.35 & 5.52 \\
$\mathrm{Si}$ & 26.74 & 28.45 & 24.30 \\
$\mathrm{Ca}$ & 1.03 & 1.52 & 0.92 \\
$\mathrm{Fe}$ & 2.86 & 2.84 & 2.56 \\
$\mathrm{~K}$ & 0.90 & 0.95 & 1.31 \\
$\mathrm{Ti}$ & 0.10 & - & - \\
$\mathrm{Cl}$ & - & - & 11.54 \\
$\mathrm{Cu}$ & - & - & $\mathbf{1 9 . 8 0}$ \\
\hline
\end{tabular}

\subsection{Kinetics and isotherms adsorption of $X O$}

The equilibrium time was $50 \mathrm{~min}$ and the adsorption capacity of VT was $17.84 \mathrm{mg} / \mathrm{g}$ (Fig. S1). The equilibrium time for orange xylenol dye adsorption reported in others works is similar to this research. Greenwald et al. (2015) reported $80 \mathrm{~min}$ as equilibrium time for XO removal onto granular activated carbon from coconuts and bituminous-based. Zhongwei and Yuanfang (2016) synthetized a magnetic hybrid $\mathrm{Fe}_{3} \mathrm{O}_{4} / \mathrm{MIL}-101$ and reported an equilibrium time of $15 \mathrm{~min}$. The equilibrium time is shorter compared with other reports for other dyes (Duman et al., 2016; Arshadi et al., 2016; Peng et al., 2016).

Pseudo second order model fitted to experimental data (Table 2). Therefore, a chemical adsorption is taking place between

Table 2

Kinetic parameters for the adsorption of xylenol orange dye onto VT mineral from aqueous solution and $\mathrm{Cu}$ (II) adsorption onto VTXO residue from ammoniacal medium.

\begin{tabular}{lcl}
\hline Kinetics parameters & $\mathrm{VT} \mathrm{q}_{\text {exp }}=17.84 \mathrm{mg} / \mathrm{g}$ & $\mathrm{VTXO} \mathrm{q}_{\text {exp }}=36.61 \mathrm{mg} / \mathrm{g}$ \\
\hline \multicolumn{2}{l}{ Pseudo first order model } & \\
$\mathrm{q}_{\mathrm{cal}}(\mathrm{mg} / \mathrm{g})$ & 17.69 & 34.97 \\
$\mathrm{~K}_{\mathrm{L}}\left(\mathrm{min}^{-1}\right)$ & 0.67 & 5.41 \\
$\mathrm{R}^{2}$ & 0.9980 & 0.9424 \\
$\mathrm{RSS}$ & 0.5486 & 61.9544 \\
Reduced Chi-square & 0.0457 & 6.1954 \\
Pseudo second order & model & \\
$\mathrm{q}_{\mathrm{cal}}(\mathrm{mg} / \mathrm{g})$ & 17.86 & 37.60 \\
$\mathrm{k}_{2}(\mathrm{~g} / \mathrm{mg} \cdot \min )$ & 0.20 & 0.009 \\
$\mathrm{R}^{2}$ & 0.9995 & 0.9955 \\
$\mathrm{RSS}$ & 0.1437 & 4.8638 \\
Reduced Chi-square & 0.0170 & 0.4864 \\
Elovich model & & \\
$\mathrm{a}(\mathrm{mg} / \mathrm{g} \cdot$ min $)$ & 10.3 & 14141.3 \\
$\mathrm{~b}(\mathrm{~g} / \mathrm{mg})$ & 1.12 & 0.36 \\
$\mathrm{R}^{2}$ & 0.9859 & 0.9968 \\
$\mathrm{RSS}$ & 3.7636 & 3.4569 \\
Reduced Chi-square & 0.3136 & 0.3457 \\
\hline
\end{tabular}


the absorbent material and the adsorbate molecules through exchange or sharing of electrons.

The adsorption of dye was carried out by a chemisorption process. Interactions between delocalized $\pi$-electrons (from the aromatic ring) or free electrons of dye molecules (present in some functional groups) and silanol groups on VT surface may occurred. The xylenol orange is an anionic dye and has $-\mathrm{SO}_{3},-\mathrm{COOH}$ and $-\mathrm{OH}$ groups, they can interact with the surface groups of the material (Fig. 4a-b). Although Tedros et al. (2017) suggested that the pseudo second order model is rare when the material in very heterogeneous, talking about its adsorbent sites, this model could also explain other interactions between surface active sites and the functional groups of dye (electrostatic interaction Fig. 4b, route 1). The $\mathrm{pH}_{\mathrm{zpc}}$ for VT (7.10) (Blanco-Flores et al., 2014) had a higher value than the one after the adsorption process (6.40). Therefore, the surface was charged positively and could attract the dye molecules through an electrostatic attraction by the $-\mathrm{SO}_{3}$ groups.

\subsection{Adsorption isotherm of dye}

The adsorption model parameters are shown in Table 3. Langmuir-Freundlich model fitted the experimental data.
Table 3

Values of the isotherm adsorption models for VT-XO and VT-XO-Cu.

\begin{tabular}{llll}
\hline Isotherm model & Parameters & VT-XO & VT-XO-Cu \\
\hline Langmuir & $\mathrm{q}_{\mathrm{m}}(\mathrm{mg} / \mathrm{g})$ & 45.17 & 33.0949 \\
& $\mathrm{k}_{\mathrm{L}}(\mathrm{L} / \mathrm{mg})$ & $2.03 \cdot 10^{-3}$ & 0.0090 \\
& $\mathrm{R}^{2}$ & 0.9520 & 0.9576 \\
Freundlich & $\mathrm{K}_{\mathrm{F}}(\mathrm{mg} / \mathrm{g} \cdot \mathrm{L})$ & 0.7080 & 11.7614 \\
& $1 / \mathrm{n}$ & 0.5481 & 0.1236 \\
Langmuir-Freundlich & $\mathrm{R}^{2}$ & 0.8964 & 0.9791 \\
& $\mathrm{q}_{\mathrm{m}}(\mathrm{mg} / \mathrm{g})$ & 30.73 & - \\
& $\mathrm{k}_{\mathrm{LF}}(\mathrm{L} / \mathrm{mg})$ & $1.48 \cdot 10^{-5}$ & \\
\multirow{5}{*}{ Temkin } & $1 / \mathrm{n}$ & 0.4990 & \\
& $\mathrm{R}^{2}$ & $\mathbf{0 . 9 8 6 7}$ & \\
\multirow{3}{*}{ Redlich-Peterson } & $\mathrm{a}(\mathrm{L} / \mathrm{g})$ & 0.0648 & 2.8585 \\
& $\mathrm{~b}$ & 6.286 & 3.5057 \\
& $\mathrm{R}^{2}$ & 0.7777 & 0.9795 \\
& $\mathrm{k}_{\mathrm{r}}$ & 0.1470 & - \\
& $\mathrm{a}_{\mathrm{r}}(\mathrm{L} / \mathrm{g})$ & 0.0311 & \\
& $\mathrm{~b}_{\mathrm{r}}(\mathrm{L} / \mathrm{mg})$ & 0.6930 & \\
& $\mathrm{R}^{2}$ & 0.9204 & \\
\hline
\end{tabular}

Bold signifies the parameter that provides information about the model that better fitted to experimental data for VT-XO material.<smiles>Cc1cc(C2(c3cc(C)c(O)c(CN(CC(=O)O)CC(=O)O)c3)OS(=O)(=O)c3ccccc32)cc(CN(CC(=O)O)CC(=O)O)c1O</smiles>

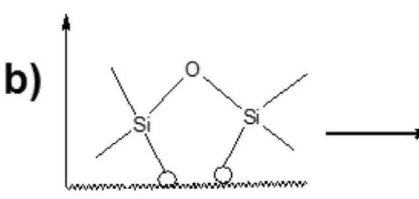

silanol surface groups
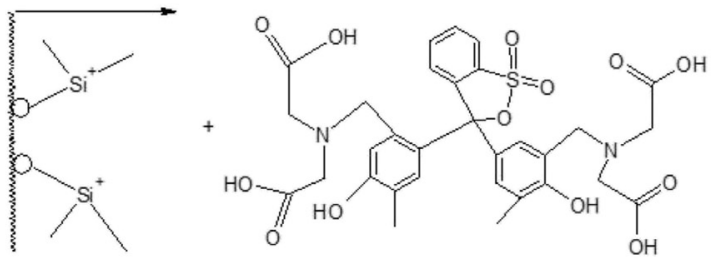

xilenol orange $(\mathrm{XO})$ dye
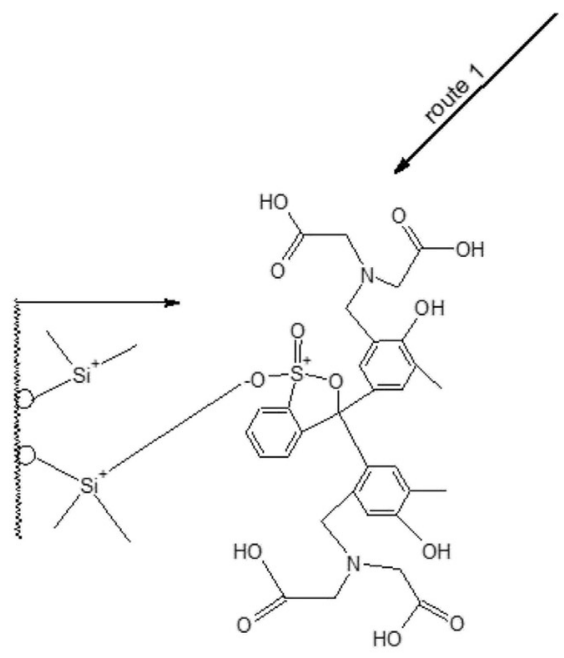

electrostatic interaction
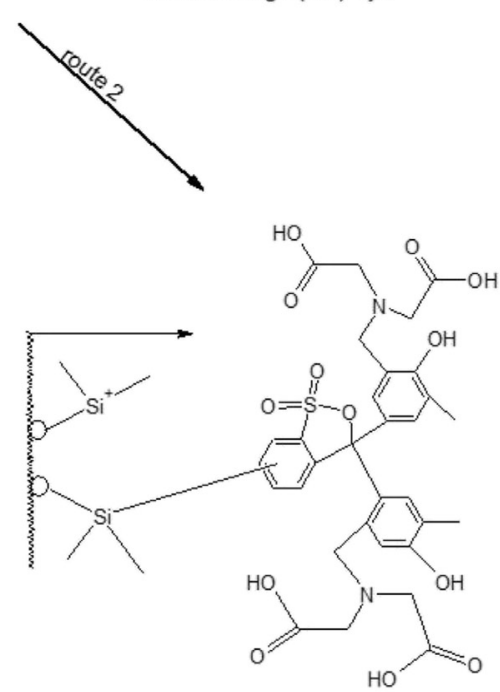

pi-electrons interaction

Fig. 4. Chemical structure of xylenol orange dye and mechanism of interaction between dye and surface groups. 
Therefore, the process was describe through a combination of mechanism onto a heterogeneous surface. The adsorption capacity of VT is $45.17 \mathrm{mg} / \mathrm{g}$. The values of constants $\mathrm{q}_{\mathrm{m}}$, $\mathrm{k}_{\mathrm{LF}}$ of LangmuirFreundlich model and $\mathrm{q}_{\mathrm{m}}, \mathrm{k}_{\mathrm{L}}$ of Langmuir model are different. This suggested that the adsorption process occurred on a heterogeneous surface. Both values of $1 / \mathrm{n}$ (from Freundlich and LangmuirFreundlich models) vary from 0 and 1 , the adsorption is favorable on a heterogeneous material (Navish et al., 2016).

The dye removal, under the established experimental conditions, could not be higher because it is limited by the superficial area, the structure of the pores and/or the chemical surface characteristics of VT. The relationship between diameter of pores and the dye molecule size was 1.1. Therefore, a strong repulsion between them is normal. Heat constant of the adsorption value, from Temkin model $(b=6.286)$, is linked to the above mentioned. Pejman et al. (2015), suggested the determination of effective surface area $\left(\mathrm{S}_{\text {eff }}\right)$ by adding the surface area from t-plot method $\left(13.3 \mathrm{~m}^{2} / \mathrm{g}\right)$ and the surface area for range of mesopores $\left(28.32 \mathrm{~m}^{2} /\right.$ g). $S_{\text {eff }}$ was $49.28 \mathrm{~m}^{2} / \mathrm{g}$, that represent the $76.5 \%$ of total surface area of VT $\left(64.4 \mathrm{~m}^{2} / \mathrm{g}\right)$. First, a fraction of pores was unavailable for dye adsorption but the removal percent of dye was $51.3 \%$. Therefore, not all $S_{\text {eff }}$ was occupied for dye molecules. To support the above statement, the coverage factor of xylenol orange was calculated for three different orientations of the XO molecule by equation (2) (Fig. 5).

$C F=\frac{q_{m} \cdot A_{x} \cdot N_{A} / 1000}{S_{e f f}}$

where $\mathrm{CF}$ is the coverage factor, $\mathrm{A}_{\mathrm{X}}$ is the cross sectional area of $\mathrm{XO}$ dye molecule at as specific orientation $(\mathrm{L}=1.39 \mathrm{~nm}, \mathrm{H}=1.22 \mathrm{~nm}$ and $\mathrm{W}=1.04 \mathrm{~nm}$ ), $\mathrm{N}_{\mathrm{A}}$ is the Avogrado's Number and $\mathrm{S}_{\mathrm{e}} \mathrm{ff}$ is the effective surface area of the VT mineral.

The values of CF is more than one for the three orientations (Fig. 5), this suggested a multilayer adsorption instead of a monolayer adsorption. Dye molecules have different functional groups charged positive or negative. Interactions between molecules may occur by any orientation of the dye molecule because all functional groups are exposed in the three orientations. This interaction could lead to the formation of hydrogen bonds and electrostatic attractions. However, the steric impediment of the molecule avoid a greater adsorption on the surface. Therefore, the main adsorption
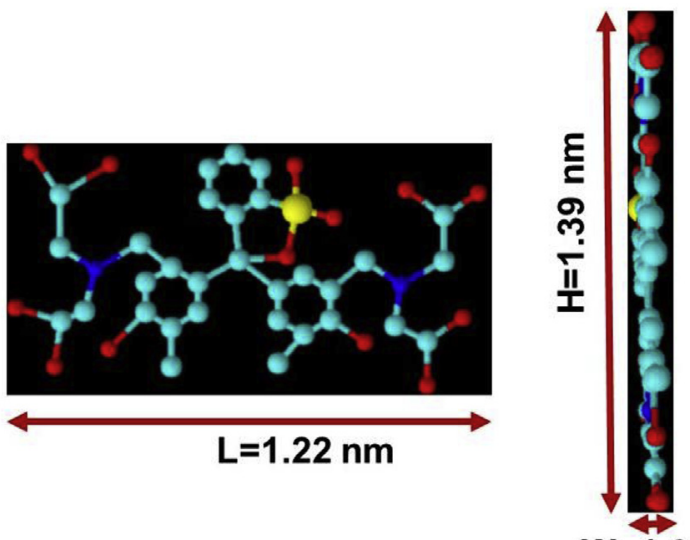

$W=1.044 \mathrm{~nm}$

\begin{tabular}{|l|l|l|}
\hline CFL & CFW & CFH $_{H}$ \\
\hline 3.63 & 2.63 & 4.64 \\
\hline
\end{tabular}

Fig. 5. Different orientation of xylenol orange dye molecule and values of coverage factor. process is taking place through multilayer interactions.

After XO adsorption a solid waste was generated (VTXO). Usually, it does not have any other use and like any other waste, without treatment, it becomes an environmental problem. For this reason, many researchers (Akar et al., 2013) had focused on reusing this waste material in others processes (Jeyashelly et al., 2013; Gómez-Martínez et al., 2013). VTXO have functional groups that may improve the heavy metals adsorption process. Since the dye adsorbed in this material has been used as indicator for the presence of some ions through complexation reaction (with $\mathrm{Ca}^{2+}, \mathrm{Pb}^{2+}$, $\mathrm{Mn}^{2+}, \mathrm{Zn}^{2+}, \mathrm{Tb}^{3+}, \mathrm{Gd}^{3+}$ )(Belleza and Villaraza, 2014), the presence of XO in VT surface can contribute to increase de amount of $\mathrm{Cu}-\mathrm{NH}_{3}$ removal. The reuse of VTXO as adsorbent material will reduced the storage of it and the cost associated with economic value will rise.

\subsection{Adsorption kinetic of $\mathrm{Cu}$ (II)}

The equilibrium time was found at $80 \mathrm{~min}$ for VTXO (Fig. S2). The value is almost twice as equilibrium time for xylenol orange dye adsorption ( $50 \mathrm{~min}$ ). This behavior should be a consequence of the slow ion diffusion produced by the dye adsorbed VTXO.

In this case, the data were adjusted with the same kinetic models (Table 2). Since Elovich model fitted well to experimental data, the $\mathrm{Cu}-\mathrm{NH}_{3}$ adsorption is a chemisorption process onto a heterogeneous surface. A different behavior was found in dye adsorption where the presence of functional groups promote the adsorption by several adsorption mechanism. The heterogeneity of VTXO could be due to the roughness of the material, the new functional groups provided by the adsorbed XO molecules and also the free adsorbent sites on VT.

\subsection{Adsorption isotherm}

The maximum adsorption capacity was $33.09 \mathrm{mg} / \mathrm{g}$. The adsorption models applied for experimental data were Langmuir, Freundlich and Temkin because Langmuir-Freundlich and RedlichPeterson did not fit correctly. According to statistical parameters Freundlich model described better the adsorption of $\mathrm{Cu}-\mathrm{NH}_{3}$. This suggested a heterogeneous adsorption on VTXO (Table 3), this result matched with the kinetic adsorption model. For this reason, it is possible to assume that the dye molecules are involved in $\mathrm{Cu}$ $\mathrm{NH}_{3}$ removal process through complexation reactions. The adsorption process was favorable considering the $1 / \mathrm{n}$ parameter from Freundlich model. This is the same behavior that happens in the determination of heavy metals by the colorimetric method, so that this result was expected. Belleza and Villaraza (2014) have reported the complexation reaction through electrostatic interactions with larger charge densities metal ions, half-filled valence and ionic radius. The "b" parameter of Temkin model was used to calculate the heat of sorption ( $\mathrm{B}$ in $\mathrm{J} / \mathrm{mol}$ ) (Erhayem et al., 2015). The values were 706.39 and $393.95 \mathrm{~J} / \mathrm{mol}$ for $\mathrm{Cu}-\mathrm{NH}_{3}$ and dye adsorption, respectively. These results suggested a chemical adsorption for both processes. The interaction was stronger for $\mathrm{Cu}-$ $\mathrm{NH}_{3}$ than for dye adsorption.

The adsorption capacity of VTXO was compared to others reported in the literature. From this result, we conclude that it is possible and suitable to use this material to remove $\mathrm{Cu}-\mathrm{NH}_{3}$ (Table 4).

\subsection{Additional comparison between VTCV and VTXO for $\mathrm{Cu}-\mathrm{NH}_{3}$ removal}

In a previous research (Blanco-Flores et al., 2014) VT was used to remove crystal violet $(\mathrm{CV})$ instead of xylenol orange (XO). In this 
Table 4

Comparison of adsorption capacities for different absorbent materials for $\mathrm{Cu}-\mathrm{NH}_{3}$ removal.

\begin{tabular}{lll}
\hline Materials & $\mathrm{q}_{\max }(\mathrm{mg} / \mathrm{g})$ & Reference \\
\hline LIX-CNT-A & 16.4 & Metwally et al., 2013 \\
LIX-CNT & 29.7 & \\
Silica/Cyanex 272 & 20.9 & \\
Mesoporous fly ash & 9.6 & \\
collagen-tannin resin & 16.9 & \\
Impregnated amberilte XAD-7 with LIX-54 & 79.9 & \\
GOS1 & 49.21 & Yang et al., 2016 \\
VTXO & $\mathbf{3 3 . 0 9}$ & This work \\
\hline
\end{tabular}

case, the adsorption material after the adsorption process was labeled as VTCV. A comparison of these two materials is described below. $\mathrm{Cu}-\mathrm{NH}_{3}$ adsorption maximum capacity was determine through Langmuir model for VT, VTXO and VTCV materials. Other models were applying to understand how the process was taking place.

The first breakthrough is that VT is not the best alternative for $\mathrm{Cu}-\mathrm{NH}_{3}$ removal. Second, Fig. S3a showed that VTXO has a higher adsorption capacity compared to VTCV, however when Langmuir model was applied the higher adsorption capacity was achieved by VTCV (Table 5). The adsorption by combination of process improve the ion adsorption regarding Langmuir-Freundlich model. The $\mathrm{Cu}-$ $\mathrm{NH}_{3}$ have more affinity for functional groups of crystal violet (Blanco-Flores et al., 2014, $\mathrm{q}_{\mathrm{m}}=174 \mathrm{mg} / \mathrm{g}$ ) than for xylenol orange dye $\left(q_{m}=33.09 \mathrm{mg} / \mathrm{g}\right)$. It could be because VT removed more crystal violet molecules than xylenol orange. However, in either case, the removal of $\mathrm{Cu}-\mathrm{NH}_{3}$ increased when mineral is modified by a dye structure (Fig. S3b).

\subsection{Experiment design factorial}

The factorial design was held to analyze the influence of solidliquid ratio (SL) and initial concentration $\left(\mathrm{C}_{0}\right)$ on the adsorption. The statistical treatment of experimental data in graphics, tables and models allowed to predict the behavior of the dependent variable as a function of the independent one.

The Pareto diagram (Fig. S4) shows all variables involved in the process and their significance level. In this case, the initial concentration has a positive influence unlike the solid-liquid relationship. This means that as the concentration of waste raised the adsorbed amount on the material surface increases. The gradient concentration allows a highest mass transfer from the solution to the adsorbent surface.

The same outcome was obtained when equation was interpreted as the multiple lineal regression model (equation (3)).

$q_{e}=48.7778+25.8333 \cdot C_{0}-23.8333 \cdot \mathrm{SL}$

$R^{2}=93.24 \%, D-W=2.31$

According to this, the concentration effect was slightly higher than the solid-liquid effect. On this basis, it was possible to assure that the concentration had a mayor influence on the response variable $\left(\mathrm{q}_{\mathrm{e}}\right)$. In order to have a better model adjustment $\mathrm{R}^{2}$ should

Table 5

Adsorption maximum capacity for VT, VTXO and VTCV material in Cu- $\mathrm{NH}_{3}$ removal.

\begin{tabular}{lll}
\hline Materials & $\mathrm{q}_{\mathrm{m}}(\mathrm{mg} / \mathrm{g})$ & Model better fitted \\
\hline VT & 19.73 & Langmuir, $\mathrm{R}^{2}=0.9654$ \\
VTXO & 33.09 & Freundlich, $\mathrm{R}^{2}=0.9791$ \\
VTCV & 71.23 & Langmuir-Freundlich, $\mathrm{R}^{2}=0.9943$ \\
\hline
\end{tabular}

be upper than 90.0\% (Gutiérrez-Pulido and Vara-Salazar, 2003). This condition was achieved with an $\mathrm{R}^{2}$ value of $93.24 \%$ for the variable $\mathrm{q}_{\mathrm{e}}(\mathrm{mg} / \mathrm{g})$. Stirring speed and temperature were maintained constant during the experiment. Therefore, the effect of these factors as well as the measurement error were small compared to the studied variable.

The statistic Durbin-Watson (D-W) demonstrated that it did not exist a serial autocorrelation between residuals. This statistic D-W should have a value close to 2 . In our case this value was 2.31 ; therefore, in this case the outcomes follow a normal distribution, they were independent.

Optimized the response allows to determinate the factor combination or experimental variable, that simultaneously streamline the process. This maximizes the desirability function corresponding to the maximum obtained value of $\mathrm{q}_{\mathrm{e}}$. The surface diagram of response (Fig. S5) relates the response optimization highlighting the local optimal zone in terms of the desirability value. From the graphic, it could be inferred that with a $\mathrm{Cu}-\mathrm{NH}_{3}$ initial concentration of $6400 \mathrm{mg} / \mathrm{L}$ it is possible to obtain an ion removal capacity of $121 \mathrm{mg} / \mathrm{g}$. However, in future papers the influence of other variables, such as temperature, $\mathrm{pH}$, mineral dose and stirring velocity will be investigated. These variables have also an influence on the adsorption process (Padilla-Ortega et al., 2014).

\subsection{Discontinuous adsorption: simple stage, cross flow and counterflow}

Adsorption isotherms can be used to predict the design of simple stage, cross flow and counterflow batch adsorption systems. Therefore, it is possible to predict the absorber behavior using the best-fit equation of the adsorption isotherm model (Kumar, 2007).

The system that required less amount of adsorbent was the counterflow batch system. This result is in agreement with specialized literature (Treybal). Fig. 6 shows the graph of mass balance for counterflow adsorber as a function of different initial concentrations of $\mathrm{Cu}-\mathrm{NH}_{3}$ and $95 \%$ of removal.

As the treated volume increased so does the adsorbent mass for different initial ion concentrations. Therefore, it is possible to estimate the cost per material to be applied in order to get a $\mathrm{Cu}-\mathrm{NH}_{3}$ specific removal percentage.

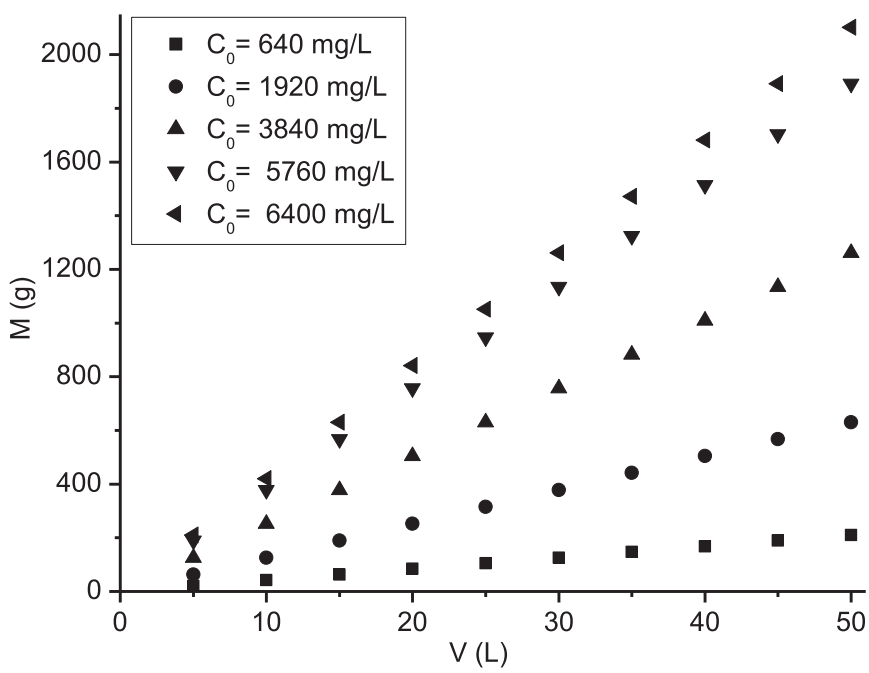

Fig. 6. VTXO adsorbent mass (M) vs. volume treated of effluent (V) for various initia ion concentration and $95 \%$ of removal at counterflow batch system. 


\subsection{Economic and technical analysis}

The economic analysis of this investigation were derived from the importance of remove $\mathrm{Cu}-\mathrm{NH}_{3}$ contained in wastewater with a solid residual coming from another process. The amount of necessary consumed VT to treat two wastewaters was compared with VTXO material to real scale of industries. The first wastewater contain R1 dye and the second $\mathrm{R} 2$ contain $\mathrm{Cu}-\mathrm{NH}_{3}$ (6000 L, Table 6).

The foregoing can be represented through Fig. 7. The obtained results realized by calculations suggested that:

1. The amount of VT mineral to treat the wastewaters in parallel process is higher than the VT amount used to treat both residuals in series.

2. Parallel treatments generate two types of solid waste, the first one with adsorbed $\mathrm{Cu}-\mathrm{NH}_{3}$ and the second one with adsorbed dye. However, for this work, just one was generated which contains both pollutants.

Table 6

Share of cost-material for using in the treatment different wastewaters (R1 and R2).

\begin{tabular}{llll}
\hline $\begin{array}{l}\text { VT amount to } \\
\text { treat R1 } \\
\text { wastewater }(\mathrm{kg})\end{array}$ & $\begin{array}{l}\text { VT amount to } \\
\text { treat R2 } \\
\text { wastewater }(\mathrm{kg})\end{array}$ & $\begin{array}{l}\text { Total amount to treat } \\
\mathrm{R} 1 \text { and R2 wastewater } \\
(\mathrm{kg})\end{array}$ & $\begin{array}{l}\text { VTXO amount to } \\
\text { treat R2 } \\
\text { wastewater }(\mathrm{kg})\end{array}$ \\
\hline 5.20 & 10.20 & $\mathbf{1 0 . 4 0}$ & $\mathbf{1 5 . 0 0}$
\end{tabular}

Bold signifies the larger amount of material when the treatment are made separately.
3. Although the amount of VTXO is greater than VT, the amount of removed metallic ion was not relevant. VTXO is a waste material whose generated quantity is higher than the needed amount to treat the effluent volume generated by the industry.

VT is a mineral; it could be found in many deposits in most countries. Generally, they are employed by ceramic and construction industries. For this reason, and taking into account the results achieved in this study, its application, as adsorbent material could be an innovative and advantageous alternative. It should allow replacing expensive materials used nowadays (Pei-Sin et al., 2014).

The reuse of solid waste, from a dye adsorption process, to eliminate $\mathrm{Cu}-\mathrm{NH}_{3}$ from an industrial wastewater contributed to save mineral. It made possible the use of less material to treat two different pollutants. In addition, VT is cheaper than the common adsorbent materials. The use of waste solid materials to remove pollutants from a wastewater leads to mitigate environmental problems. At the same time, the generated solid waste from XO removal is an efficient material to adsorb heavy metals such copper even in ammoniacal medium.

\section{Conclusion}

The adsorption process of xylenol orange dye reached the equilibrium within $50 \mathrm{~min}$, being the process a chemical adsorption. The maximum adsorption capacity of XO with VT is $45.17 \mathrm{mg} /$ g. Removal time of $\mathrm{Cu}-\mathrm{NH}_{3}$ with VTXO was higher than the needed time for the dye removal. The process was held by chemical and

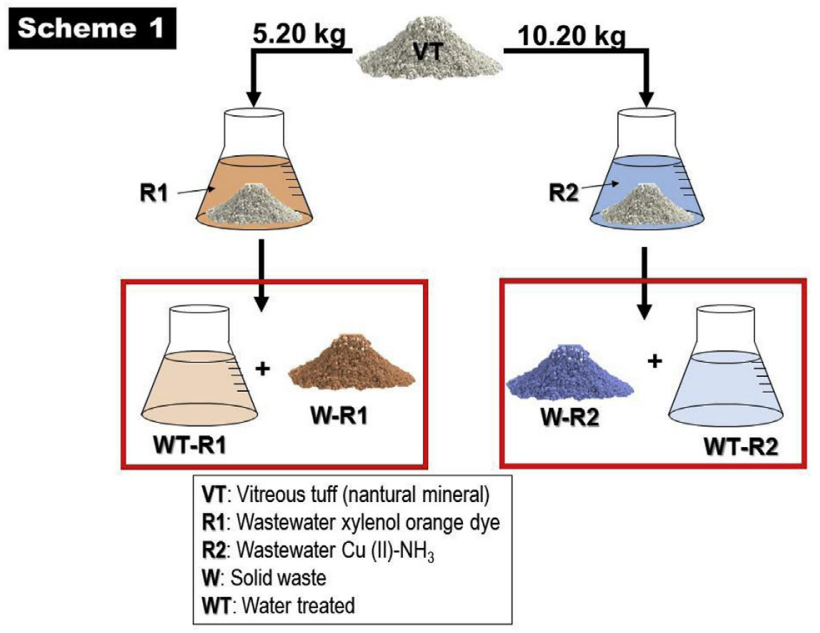

Scheme 2
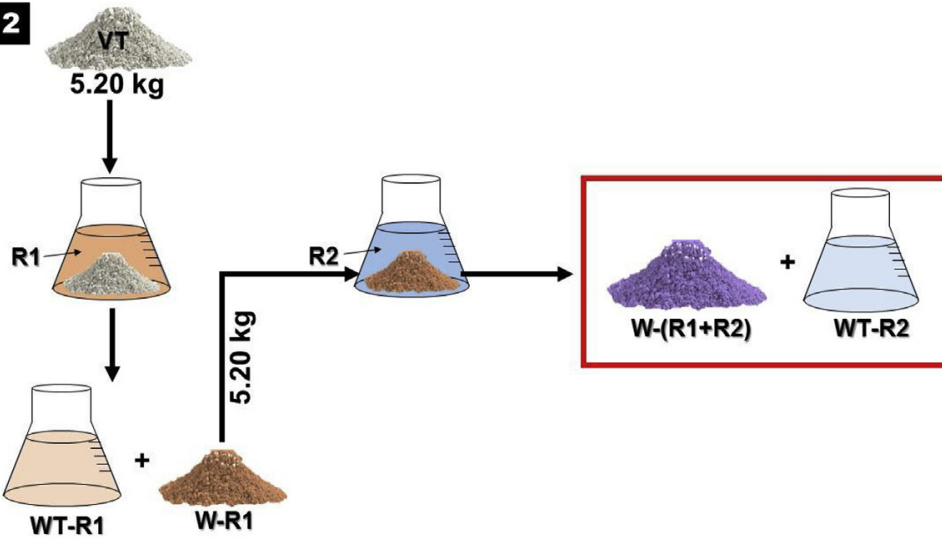

Fig. 7. Economical and technical analyses obtained from the results of this investigation. 
physical adsorption. The experimental isotherm was adjusted to Freundlich and Langmuir-Freundlich models with an adsorption capacity of $33.09 \mathrm{mg} / \mathrm{g}$ on a heterogeneous surface. A multilayer adsorption and a combination of interactions took place during this process. The analysis of experimental design showed that the maximum adsorption value was obtained with an initial ion concentration of $6400 \mathrm{mg} / \mathrm{L}$ and a solid-liquid relationship of $10 \mathrm{~g} / \mathrm{L}$. The proposed alternative to treat $\mathrm{Cu}-\mathrm{NH}_{3}$ from wastewater industry, using a solid waste material, demonstrated to be more viable than the method with natural one. The design of absorbers demonstrated that the best system, that required lower amount of absorbent material, was the counterflow batch system.

\section{Acknowledgements}

We thank Dr. Miguel A. Autié Pérez for the knowledge he provided for the realization of this research article.

\section{Appendix A. Supplementary data}

Supplementary data related to this article can be found at https://doi.org/10.1016/j.jenvman.2017.11.074.

\section{References}

Aguiar, J.E., Cecilia, J.A., Tavares, P.A.S., Azevedo, D.C.S., Rodríguez-Castellón, E., Lucena, S.M.P., Silva, J.I.J., 2017. Adsorption study of reactive dyes onto porous clay heterostructures. Appl. Clay Sci. 135, 35-44.

Akar, E., Altinişik, A., Seki, Y., 2013. Using of activated carbon produced from spent tea leaves for the removal of malachite green from aqueous solution. Ecol. Eng. $52,19-27$.

Anirudhan, T.S., Ramachandran, M., 2015. Adsorptive removal of basic dyes from aqueous solutions by surfactant modified bentonite clay (organoclay): kinetic and competitive adsorption Isotherm. Process Saf. Environ. Protect. 95, 215-225.

Arshadi, M., Mousavinia, F., Amiri, M.J., Faraji, A.R., 2016. Adsorption of methyl orange and salicylic acid on a nano-transition metal composite: kinetics, thermodynamic and electrochemical studies. J. Colloid Interface Sci. 483, 118-131.

Ávila, C.R., 2011. Remoción de azul de metileno en agua empleando bagazo de Agave Salmiana como biosorbente. Tesis de Maestría.

Belleza, A., Villaraza, V., 2014. Ion charge density governs selectivity in the formation of metal-Xylenol Orange (M-XO) complexes. Inorg. Chem. Commun. 47, $87-92$.

Blanco-Flores, A., Colin-Cruz, A., Gutierrez-Segura, E., Sanchez-Mendieta, V., SolisCasados, D.A., Garrudo-Guirado, M.A., Batista-Gonzalez, R., 2014. Efficient removal of crystal violet dye from aqueous solutions by vitreous tuff mineral. Environ. Technol. 35, 1508-1519.

Blanco-Flores, A., Gutiérrez-Segura, E., Sánchez-Mendieta, V., Vilchis-Néstor, A.R. 2016. Removal of malachite green dye from aqueous solution through inexpensive and easily available tuffite, bentonite and vitreous tuff minerals. Revista Latinoamericana de Recursos Naturales 12, 1-17.

Can, N., Ömür, B.C. Altindal, A., 2016. Modeling of heavy metal ion adsorption isotherms onto metallophthalocyanine film. Sensor. Actuator. B 237, 953-961.

Duman, O., Tunç, S., Bozoglan, B.K., Polat, T.G., 2016. Removal of triphenylmethane and reactive azo dyes from aqueous solution by magnetic carbon nanotube-kcarrageenan- $\mathrm{Fe}_{3} \mathrm{O}_{4}$ nanocomposite. J. Alloys Compd. 687, 370-383.

Erhayem, M., Al-Tohami, F., Ragwan, M., Khadija, A., 2015. Isotherm, kinetic and thermodynamic studies for the sorption of mercury (II) onto activated carbon from Rosmarinus Officinalis leaves. Am. J. Anal. Chem. 6, 1-10.

Feng, Yi., Wang, Y., Liu, S., Jiang, J., Cao, C., Yao, J., 2017. Simple fabrication of easy handling millimeter-sized porous attapulgite/polymer beads for heavy metal removal. J. Colloid Interface Sci. 502, 52-58.

Ge, Y., Cui, X., Kong, Y., Li, Z., He, Y., Zhou, Q., 2015. Porous geopolymeric spheres for removal of $\mathrm{Cu}(\mathrm{II})$ from aqueous solution: synthesis and evaluation. J. Hazard Mater. 283, 244-251.

Gómez-Martínez, G., López-Montelongo, A.M., Maser-Froto, L., 2013. Industrialización de la vivienda popular utilizando materiales reciclados. Asinea 42 $27-33$.

Greenwald, M.J., Redding, A.M., Cannon, F.S., 2015. A rapid kinetic dye test to predict the adsorption of 2-methylisoborneol onto granular activated carbons and to identify the influence of pore volume distributions. Water Res. 68, 784-792.

Gutiérrez-Pulido, H., Vara-Salazar, R., 2003. In: Análisis y diseño de experimentos. Mc Graw Hill Interamericana, México.

Heide, K., Heide, G., 2011. Vitreous state in nature-Origin and properties. Chemie der Erde Geochem. 71, 305-335.

Jeyashelly, A., Farook, A., Rahman, I.A., 2013. Heterogeneous copper-silica catalyst from agricultural biomass and its catalytic activity. Appl. Surf. Sci. 284 503-513.

Kumar, K.V., 2007. Batch adsorber design for different solution volume/adsorbent mass ratios using the experimental equilibrium data with fixed solution volume/adsorbent mass ratio of malachite green onto orange peel. Dyes Pigments 74, 590-594.

Metwally, S.S., Hassan, M.A., Aglan, R.F., 2013. Extraction of copper from ammoniacal solution using impregnated amberlite XAD-7 resin loaded with LIX-54. J. Environ. Chem. Eng. 1, 252-259.

Navish, K., Garg, V.K., Jain, M., Kadirvelu, K., 2016. Preparation, characterization and potential use of flower shaped zinc oxide nanoparticles (ZON) for the adsorption of victoria blue B dye from aqueous solution. Adv. Powder Technol. 27, $1180-1188$.

Padilla-Ortega, E., Leyva-Ramos, R., Mendoza-Barron, J., 2014. Role of electrostatic interactions in the adsorption of cadmium (II) from aqueous solution onto vermiculite. Appl. Clay Sci. 88-89, 10-17.

Pei-Sin, K., Siew-Ling, L., Sie-Tiong, H., Yung-Tse, H., Siew-Teng, O., 2014. Removal of hazardous heavy metals from aqueous environment by low-cost adsorption materials. Environ. Chem. Lett. 12, 15-25.

Pejman, H., Yeung, K.Y., Barford, J., Jin, A.K., McKay, Gordon, 2015. Significance of "effective" surface area of activated carbons on elucidating the adsorption mechanism of large dye molecules. J. Environ. Chem. Eng. 3, 1029-1037.

Peng, H.H., Chen, J., Jiang, D.Y., Li, M., Feng, L., Losic, D., Dong, F., Zhang, Y.X., 2016. Synergistic effect of manganese dioxide and diatomite for fast decolorization and high removal capacity of methyl orange. J. Colloid Interface Sci. 484, 1-9.

Pichór, W., Janiec, A., 2009. Thermal stability of expanded perlite modified by mullite. Ceram. Int. 35, 527-530.

Tedros, M.B., Levy, J., Krekeler, M.P.S., Danielson, Neil. D., 2017. Kinetic sorption of contaminants of emerging concern by a palygorskite-montmorillonite filter medium. Chemosphere 176, 231-242.

Treybal, R.E. Operaciones de transferencia de masa. Segunda ed., New York, ISBN 9686046348.

Tsai, W.T., Chen, H.P., Lai, C.W., Hsien, K.J., Lee, M.S., Yang, J.M., 2003. Preparation of adsorbents from sugarcane manufacturing by-product filter-mud by thermal activation. J. Anal. Appl. Pyrol. 70, 399-411.

Wu, S., Bing, L., Sun, W., Su, S., Ding, S., 2014. Adsorption of Congo red from aqueous solution onto pyrolusite reductive leaching residue. Desalin. Water Treat. 52, 3564-3571.

Yang, L., Hu, J., Wu, W., Tang, J., Ding, K., Li, J., 2016. In situ $\mathrm{NH}_{2}$-functionalized graphene oxide $/ \mathrm{SiO}_{2}$ composites to improve $\mathrm{Cu}$ (II) removal from ammoniacal solutions. Chem. Eng. J. 306, 77-85.

Zhang, L., Zhang, G., Wang, S., Peng, J., Cui, W., 2016. Cation-Functionalized silica nanoparticle as an adsorbent to selectively adsorb anionic dye from aqueous solutions. Environ. Prog. Sustain. Energy 35, 1070-1077.

Zhongwei, J., Yuanfang, L., 2016. Facile synthesis of magnetic hybrid $\mathrm{Fe}_{3} \mathrm{O} / \mathrm{MIL}-101$ via heterogeneous coprecipitation assembly for efficient adsorption of anionic dyes. J. Taiwan Inst. Chem. Eng. 59, 373-379. 